\title{
VISÃO DE CAUSALIDADE: MERLEAU-PONTY EM MICHOTTE
}

\author{
Causality Seeing: Merleau-Ponty on Michotte \\ Visión de Causalidad: Merleau-Ponty en Michotte
}

LESTER EMBREE

\begin{abstract}
Resumo: A apreciação de Merleau-Ponty pela descrição de causação percebida de Michotte é apresentada com algumas explicações baseadas no livro de Michotte e depois no contexto das três estruturas formadoras do comportamento e também as distinções de atividade e passividade primária e secundária no Meditações Cartesianas de Husserl.

Palavras-chave: Fenomenologia; Merleau-Ponty; Michotte.
\end{abstract}

\begin{abstract}
Merleau-Ponty's appreciation of Michotte's description of seen causation is presented with some explication on the basis of the latter's book and then in the context of the former's three structures of behavior as well as the distinctions of activity and primary and secondary passivity in Husserl's Cartesianische Meditation.

Keywords: Phenomenology; Merleau-Ponty; Michotte.

Resumen: El análisis de Merleau-Ponty en la descripción de causación percibida por Michotte es presentada con algunas explicaciones basadas en el libro de Michotte y después en el contexto de las tres estructuras formadoras de las conductas. También, en las distinciones de actividad y de pasividad primaria y secundaria en las Meditaciones Cartesianas de Husserl.

Palabras-clave: Fenomenología; Merleau-Ponty; Michotte.
\end{abstract}

L'enfant voit l'objet A produire le movement de B; il en perçoit la relation de causalité

(“Structure et conflits de la conscience enfantile," p. 185)

\section{Introdução}

Em Merleau-Ponty's Examination of Gestalt Psychology (Embree, 1980), observei que,

(...) a Gestaltung em Michotte [La Perception de Causalité (1946)] foi também apreciada após a guerra; infelizmente este trabalho não precedeu [Fenomenologia da Percepção (1945)], dessa forma aquele magnus opus provavelmente teria um grande lugar para a causação vivida (p. 91).

Essa intimação de que a pesquisa de Baron Albert Michotte van den Berck (1881-1965) não foi apreciada por Merleau-Ponty porque foi publicado após 1945 pode estar, de alguma forma, errada. Michotte publicou La causalité physique est-elle une donnée phenomenale? em 1941, embora a guerra possa ter rompido a comunicação entre Bélgica e França neste momento. Além disso, Michotte era um eminente psicólogo experimental que vinha publicando desde 1904, achou seu trabalho convergente com a Psicologia da Gestalt desde o início dos anos 20 (ele se refere a Dunker, Katz, Koffka, Köhler, Metzger, Rubin, e Wertheimer), publicando seu Rapport sur la perception des formes em um simpósio na Gestalt-wahrnehmung em 1926, e começou estendendo os conceitos gestálticos anteriormente focalizados no domínio sensorial ao campo motor, lecionando "Psicologia da Ação" no College de France em 1937 e publicando L'étude morphologique des reactions motrices em 1938 (Boring, 1952).

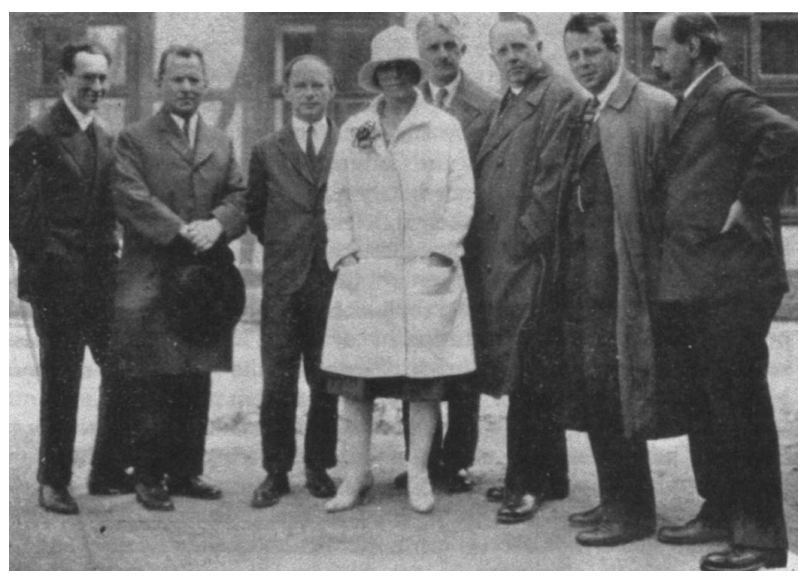

Figura $1^{1}$

Claro, Merleau-Ponty estava interessado na teoria da Gestalt desde o início dos anos 30 e assim deve ter conhecido Michotte. $\mathrm{O}$ fato de eu estar otimista sobre como A Fenomenologia da Percepção poderia ter sido diferente será o ponto no qual começarei a discutir abaixo.

\footnotetext{
Rostock, 1928. Da esquerda para a direita: Kurt Lewin, David Katz, Heinz Werner, Madame Katz, Wolfgang Köhler, Albert Michotte, Edgar Rubin e Max Wertheimer. (Fritz Heider também esteve nesse encontro, mas nao aparece nesta foto).
} 
A apreciação de Merleau-Ponty sobre o livro de Michotte após 1945 é interessante fenomenologicamente e, até onde sei, não foi estudado anteriormente ${ }^{2}$, talvez porque a base textual de seus escritos para interpretar aquela apreciação seja escassa e dispersa e La perception de la causalité possa erroneamente ter sido visto como um trabalho excessivamente grande e técnico (Michotte, 1963).

Com alguma explicação baseada em Michotte, a apreciação de Merleau-Ponty será apresentada na primeira parte do seguinte ensaio, e então uma tentativa será feita para reconstruir a partir de Husserl e também de MerleauPonty como a análise de Michotte se correlaciona com a passividade primária.

\section{A Apreciação de Merleau-Ponty sobre Michotte}

É uma das virtudes exemplares de Merleau-Ponty ter procurado aprender com cientistas experimentais, principalmente dos psicólogos da tendência gestaltista. Esse exemplo foi seguido, mais tarde, por colegas com respeito à Ciência Cognitiva, mas algum deles poderia desejar por mais consideração fenomenológica há algum tempo, como David Katz em relação à cor e ao tato, por exemplo. $\mathrm{E}$, apenas a respeito de Michotte, existem títulos promissores após La perception de la causalité como "La perception de la fonction 'outil"' (1951), "Perception et causation" (1955), e "Réflexions sur le rôle de langage dans l'analysis des organizations perceptives" (1959) que poderiam ter sido levados em consideração. Mas Merleau-Ponty parece se referir claramente apenas a La perception de la causalité e faz muito bem em "Structure et conflits de la conscience infantile", mas se refere novamente mais significativamente em A Natureza e em O Visível e o Invisível.

Em especial, dois componentes do trabalho de Michotte interessaram Merleau-Ponty. Aquele relacionado à "percepção dos verdadeiros movimentos vitais de auto-locomoção tais como a reptação ou a natação" não será discutido no presente ensaio, mas merece menção de que humanos são, em si mesmos, muitas vezes, causas e efeitos, que pessoas geralmente descrevem as coisas como se elas estivessem vivas, como por exemplo, retângulos coloridos se mexendo que parecem movimentar suas cabeças e puxar seus rabos e são regularmente chamados de lagartas e vermes pelas pessoas (Michotte, 1963, p. 183-185) e que, além disso, existem algumas observações em Michotte sobre o corpo cinestésico e sobre ações voluntárias (Michotte, 1963, p. 205 \& 212) que são admitidamente não-sistemáticos, mas merecem um estudo separado.

\footnotetext{
Herbert Spiegelberg (1972) discute Michotte nas páginas 63-67 de seu livro Phenomenology in Psychology and Psychiatry, mas não menciona nenhuma conexão com Merleau-Ponty. A conexão também não é surpreendentemente mencionada em Michotte’s Experimental Phenomenology of Perception (Thinès, Costall \& Butterworth, 1991).
}

O componente relacionado à causalidade mecânica será focalizado aqui. Este é mais facilmente introduzido em relação à figura posterior. Merleau-Ponty descreve o que essa figura ilustra:

Através de uma tela furada por uma fenda, o sujeito vê uma segunda tela sobre a qual são projetados dois quadrados: um A, à esquerda e o outro B no meio. Sob os olhos do observador, o quadrado se movimenta para a direita, se junta ao quadrado B e pára. O quadrado B, por seu turno, se coloca em movimento: em certas condições, o observador terá a impressão que é A que comunicou seu movimento a B; ele terá a percepção de um fenômeno causal, de um "efeito-lançamento" ("effetlancement”) (Merleau-Ponty, 1964, p. 186).

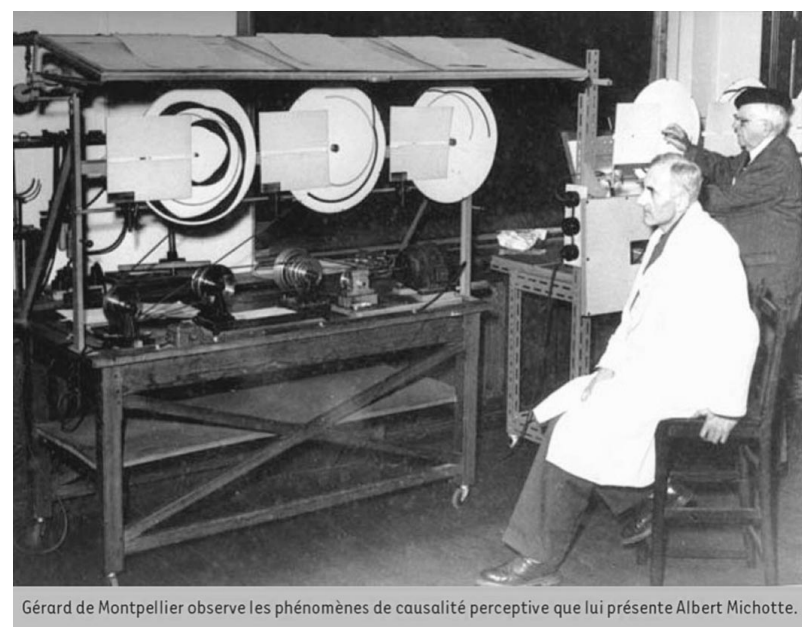

Figura $2^{3}$

Então, Merleau-Ponty oferece mais comentários:

1. Esse caso de causação ocorre em condições estritas que não são de ordem intelectual, mas sim perceptual, por exemplo, condições topográficas, espaciais e temporais;

2. Se A e B estão presentes na tela no momento do contato, tem-se a impressão de que apenas um quadrado é movido da esquerda para a direita;

3. A visão precisa estar focalizada - se o contato ocorre na margem do campo visual, existe um efeito de "túnel" de que A passa atrás de $B$ e se move;

4. A distância entre A e B e o curso do movimento de $B$ não precisa ser muito grande. Após um certo limite, o efeito de lançamento (effet-lancement) não é produzido e os dois quadrados parecem continuar por si mesmos;

5. Pela variação das velocidades e das trajetórias, é possível se obter outros efeitos além do efeito de lançamento como o lançamento em vôo (lancement-en-vol) e o Efeito Incorporador (l'effet entraînement);

6. O efeito de lançamento é destruído por várias mudanças no campo perceptual, por exemplo, por rodear B com objetos que não se movem ou adicionando um terceiro objeto à direita de $\mathrm{B}$ que se move para cima na direção oposta de A; e

\footnotetext{
Gerard de Montpellier observa os fenômenos de causalidade perceptiva que lhe são apresentados por Albert Michotte.
} 
7. Existe um efeito de expulsão quando B se move mais rápido após contato, que A se moveu para contatálo.

Então Merleau-ponty novamente fala de uma maneira mais geral:

De tomar de mais perto a impressão de lançamento; o fenômeno é sempre percebido pelos sujeitos como um fenômeno global, como um todo pertencente a uma só força e jamais se pudesse agir de dois movimentos: antes como uma metamorfose do movimento de A no movimento de B: É uma causalidade transitiva, os dois movimentos fazendo parte de uma mesma "linha de mundo", a uma só linha de força. Foi dissociando os dois movimentos que Hume e Malebranche chegaram a negar a causalidade objetiva e a reduzir o movimento a um simples deslocamento. De fato há uma diferença surpreendente entre movimento e deslocamento, que Michotte coloca igualmente em evidência: ele substitui o efeito de lançamento (movimento) por um efeito de "transporte" (deslocamento massivo) obtido logo que A se junta a B e que os dois permanecem juntos; temos então a impressão que A transporta B ("A se move", "B é deslocado") (Merleau-Ponty, 1964, p. 186).

\section{PHENOMENAL CAUSALITY}
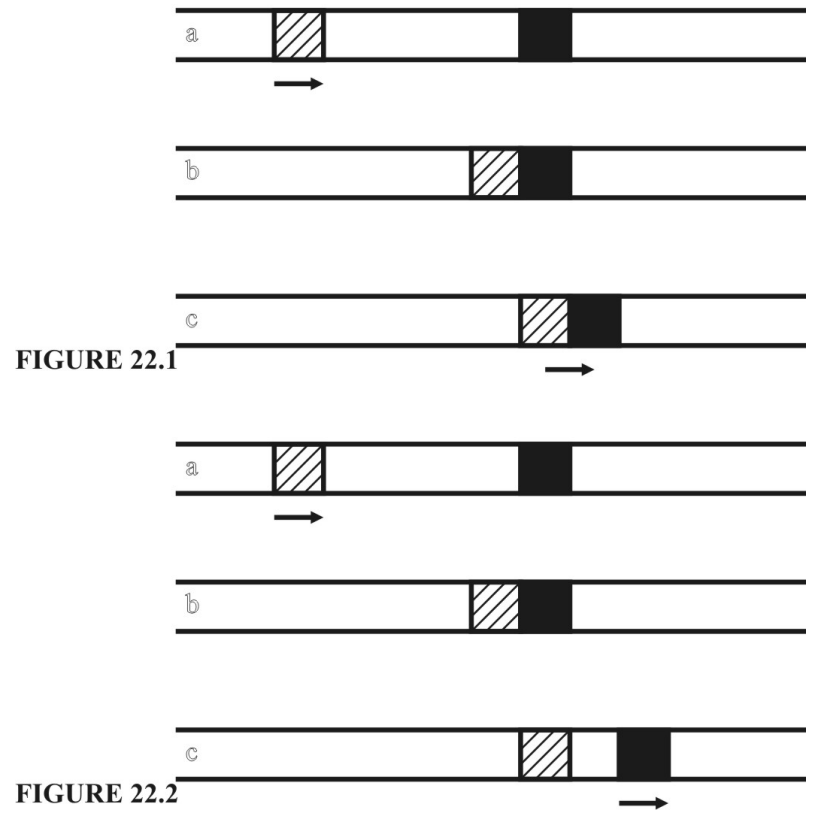

Figuras 2.1 e $2.2^{4}$

${ }^{4}$ Representação esquemática de dois experimentos básicos. As letras a, b e c indicam as posições dos objetos se movendo em diferentes momentos dos experimentos. As setas abaixo dos objetos indicam que eles estão em moção (movimento) e em uma direção no momento considerado. A posição dos objetos no momento crucial é representada sem setas, mesmo que um dos objetos, ou ambos, estejam em movimento naquele momento. As áreas entre os blocos representam os caminhos que podem ser percorridos até o fim dos tubos, permitindo ao experimentador variar seu comprimento em experimentos particulares.
Para Michotte existem dois tipos principais de causalidade, aquele que produz o efeito de lançamento (Figura 2.2) e aquele que produz o efeito incorporador (Figura 2.1). (Os tradutores americanos consideram "entraining" como uma expressão pouco usual, mas não chega a ser um neologismo). Em ambos os tipos há uma questão da impressão de movimento sendo transferida de um objeto, que pode ser chamado de "A", para um outro que pode ser chamado de "B". No tipo formador, "os observadores vêem o objeto A 'entrar' no objeto B e mandá-lo para fora (ou lançá-lo), empurrá-lo para cima, colocá-lo em movimento, dar um empurrão. A impressão é clara; é o sopro dado por A que faz B continuar; que produz o movimento de B" (Michotte, 1963, p. 20). No último tipo, "nós temos a impressão de que o objeto A carrega B (ou incorpora ele), que um pega o outro, que ele ganha velocidade na passagem, ou novamente, se a velocidade e o tamanho do objeto são modificados, ele empurra-o para frente. A impressão de causação está novamente clara; é A que faz B ir em frente, que produz mudança de posição em B". (Michotte, 1963, p. 21).

Variações são discutidas em relação a esses dois tipos. Enquanto no "lançamento por empurrão", A pára e B se move na velocidade que A tinha (Michotte, 1963, p. 87), existe o "lançamento por expulsão" onde B se move mais rápido após o contato do que A estava se movendo quando eles se contataram (Michotte, 1963, p. 90). Como Merleau-Ponty também menciona, existe um efeito-túnel por onde A parece ir abaixo ou através de B e depois continua (Michotte, 1963, p. 49). Então existe uma repercussão onde A entra em contato com B e então se movimenta para trás dando a impressão de não afetar B. E então novamente, B pode já estar em movimento e A se chocar com ele, entrar em contato com ele, e parecer aumentar sua velocidade (Michotte, 1963, p. 69 ff).

Incorporar, em geral, requer itens se movendo na mesma velocidade e na mesma direção após o contato, enquanto no efeito de lançamento, o objeto A pára ou diminui de velocidade enquanto $\mathrm{B}$ continua com a velocidade que A tinha ou, no efeito de expulsão, ele vai ainda mais rápido que A. Na variação do efeito incorporador, chamada de "efeito de transporte", o movimento pertence ao veículo e não ao objeto que é carregado, que permanece passivo e é meramente deslocado, e não está ativo em uma maneira derivada. No transporte puro, A e B se movem juntos desde o começo e não há impressão causal. A impressão causal requer que as duas coisas permaneçam distintas e que A de alguma maneira domine no movimento dos dois (155 f.). Existe também o tipo de incorporação chamada de "efeito tração", no qual A vai para frente de B e B é puxado e não empurrado. Finalmente, quando uma flecha é atirada em um alvo ou um dardo é arremessado por um braço, existe uma incorporação de duas coisas se movendo juntas, seguidas pelo lançamento de um projétil e a causa é reconhecida na incorporação por sua mudança de forma. 
Isso tudo está na explicação dada de forma claramente direta por Merleau-Ponty em "Structure et conflits de la conscience enfantine".

\section{Questões mais Profundas}

O fenomenólogo é simpático com a análise de Michotte e se refere a ela repetidamente depois, mas existem aspectos que merecem maiores comentários, e podem ter sido pontos para diferenças na Fenomenologia da Percepção, como eu especulei.

Em primeiro lugar, e como a figura acima mostra, o sujeito experimental enxerga e descreve o que acontece em uma parte de um aparato complicado. O que ele vê são quadrados ou retângulos oblongos de uma ou duas cores. Bildbewusstsein não está envolvida aqui como nas figuras gestálticas familiares como a do coelho/pato, mas existe uma ilusão que as pessoas vêem imediatamente:

Foi então que eu tive a boa sorte de pensar na possibilidade de produzir sistematicamente combinações de movimentos de alguns objetos por fazer uso da bem conhecida ilusão do movimento que ocorre quando uma linha se move atrás de uma tela tendo um tubo fazendo um ângulo com a linha. Por essa técnica, eu consegui de uma só vez realizar um experimento pretendido para representar o caso do impacto de duas bolas de bilhar (realmente dois tipos de cores) e o resultado era óbvio. Todos os observadores concordaram em afirmar que eles estavam "vendo um dos objetos bater no outro e movendo-o" (Autobiografia, Op. Cit. pág. 228, cf. 232).

Em segundo lugar, Michotte regularmente fala de "impressões”. Ele mesmo diz:

(...) eu prefiro usar a frase "impressão causal" a "percepção de causalidade" que é o título desse livro. Embora em minha opinião elas sejam equivalentes, eu acho, talvez, que as palavras "impressão causal”, que eu devo usar regularmente no resto do artigo, traz mais claramente a idéia de um dado imediato, de algo diretamente "vivido" (cf. A palavra alemã 'Erlebnis'). Assim 'impressão causal' poderia ser traduzida como Verursachungserlebnis' (Michotte, 1963, p. 15).

Em terceiro lugar, a coisa vista pode ser descrita pelos sujeitos em termos animísticos pelos quais A faz algo para B, mas o movimento das coisas em situações causais vistas parece considerado por Michotte como sendo, poderia ser dito, coisas naturais. Ao contrário, as bolas de bilhar de Hume são coisas naturais com funções na vida prática. Como uma coisa natural é derivada de uma coisa cultural, quando a atitude personalista, ou melhor, cultural é reduzida a uma atitude natural, poderia ter sido discutido por Merleau-Ponty, que era familiar com o não publicado Ideen II [1913] desde que ele visitou os arquivos de Husserl em 1939, mas ele não discute.

Embora Michotte descreva em termos naturalistas o que seu sujeito vê, ele mesmo busca refúgio em termos mundanos para discuti-los, por exemplo:

(...) eu citei vários exemplos nessa conexão, aquele de uma unha sendo martelada numa prancha e aquele de uma faca cortando um pedaço de pão, por exemplo. A questão que surge aqui é essa: quando nós observamos essas operações, nossa percepção é limitada à impressão de dois movimentos espacialmente ou temporalmente coordenados, tal como o avanço da faca e o corte do pão? Ou então nós percebemos diretamente a ação como tal - nós vemos realmente a faca cortar o pão? (Michotte, 1963, p. 15).

Em quarto lugar, a análise de Michotte é oculocêntrica e Merleau-Ponty não comenta como uma modalidade sensorial pode vir a predominar na percepção sinestésica, mas ele parece reconhecer que existe predominantemente causalidade auditória:

Quando teóricos da Gestalt mostram que a percepção do movimento depende de muitos momentos figurais e, finalmente, da estrutura completa do campo, eles estão esboçando na mesma direção que o sujeito que percebe um tipo de aparato de pensamento que é seu ser habitual e encarnado. A realização de movimento e a mudança de localidade emanam de uma estrutura de campo à parte que são não-inteligíveis. Os estudos de Michotte têm mostrado todas as transições entre as configurações e a percepção de movimento; por exemplo, como os movimentos de "natação" e "reptação" surgem de cada articulação e lógica interna dos fenômenos (Merleau-Ponty, 1970, p. 6).

Em quinto lugar, enquanto os experimentos de Michotte são realizados com adultos, Merleau-Ponty curiosamente expõe Michotte na direção da psicologia infantil. Como é isto, para aquele problema, e a extensão para a qual a vida mental não-humana é possível? "Sem dúvidas, uma das mais importantes aquisições dessa teoria tem sido o domínio das alternativas clássicas entre a psicologia objetiva e a psicologia introspectiva. A psicologia da Gestalt foi além dessa alternativa por mostrar que o objeto da psicologia é a estrutura do comportamento, acessível por dentro e por fora"5. Não apenas essa posição ajuda a clarificar a relação entre $A$ Estrutura do Comportamento e a Fenomenologia da Percepção, mas também legitima a observação comportamental onde não existem possíveis respostas subjetivas, por exemplo, na investigação de chimpanzés e aranhas.

\footnotetext{
Ver Maurice Merleau-Ponty, "Le primat de la perception et ses consequences philosophiques" (1947)="The Primacy of Perception and its Philosophical Consequences," trans. James M. Edie, in The Primacy of Perception and Other Essays (Evanston, Ill: Northwestern University Press, 1964), p. 23, cf. $185=\mathrm{BP}$ 197. The allusion is to Paul Guillaume's “L’Objectivité en psychologie” (1932), referred to in Phénoménologie de la perception as well as La Structure du comportement.
} 
Em sexto lugar, como a análise gestaltista de Michotte da causalidade vista se relaciona às três espécies de estruturas comportamentais introduzidas na segunda parte de A Estrutura do Comportamento e referidas novamente nas Leituras na Sorbonne (Merleau-Ponty, 1964, p. 139)? Merleau-Ponty concorda com Michotte que os experimentos dizem respeito à percepção sem ou ao menos anteriormente à intelecção. Portanto, causalidade vista não é um problema de formas simbólicas. O próprio Michotte escreve:

(...) no caso desses dois experimentos, a produção de movimento é experienciada diretamente. Não há questão de interpretação, nem de "significância" sobreposta na impressão de movimento; em outras palavras, o que é realmente "dado" não é uma mera representação ou um símbolo de causalidade (Michotte, 1963, p. 21).

Novamente então, formas mutáveis ou restituíveis (amovibles) envolvem aprendizagens, sinais, e objetos culturais por Merleau-Ponty e, portanto, também não é o caso para a causalidade vista entre retângulos naturais em indícios descobertos por Michotte. Por isso, apenas pelo processo de eliminação, a causalidade vista é uma forma sincrética, algo que é instintual.

Em sétimo e último lugar, existe uma trifurcação em Edmund Husserl que é altamente convergente com as três estruturas de comportamento de Merleau-Ponty. Está nas Meditações Cartesianas (1931, §§38, 39 \& 51), um trabalho que Merleau-Ponty conhecia por completo e onde causalidade é relacionada à primordialidade no §61. Para Husserl existe, (a) um estrato de atividades mais alto no qual o Eu está engajado e objetos são originalmente formados categorialmente; (b) um estrato médio, poderia ser dito, de passividade secundária no qual o Eu estava anteriormente engajado e posso me engajar novamente, mas no qual a Erlebnisse rotineiramente continua sem aquele engajamento e no qual a cultura básica é fortemente constituída; e (c) um estrato inferior de passividade primária no qual eu não posso me engajar, e no qual a natureza espacial, temporal e causal é fenomenologicamente constituída antes de qualquer formação conceitual.

Merleau-Ponty parece ter conhecido isso, para ele escrever nos cursos de 1956-57, La Nature, que:

A Fenomenologia quer descobrir uma passividade original, em oposição á passividade secundária de hábito. A "síntese passiva", que apenas me faz perceber a coisa, nunca é pensada como um produto da construção do Eu. Atividade é apenas um setor da consciência. O que é criado pela atividade de seres humanos são objetos culturais, ou "idealizações", como Husserl disse no fim da vida (MerleauPonty, 2003, p. 71).

A causalidade de Michotte é discutida nos cursos de 1957-58 também, "uma continuidade entre causa e efei- to" (Merleau-Ponty, 2003, p. 155) sendo mencionada, mas não está explicitamente conectada com a passividade primária de Husserl.

O mais próximo que Merleau-Ponty chega para reconhecer a convergência com Husserl parece ser essa passagem de "Les Relations avec autrui chez l'enfant":

$[\mathrm{N}]$ o caso de relações causais, que tem sido tradicionalmente pensadas como ensinadas por uma operação intelectual na criança, ao contrário, nós temos visto, com Michotte, que tais relações são ancoradas na percepção total de eventos externos da criança e aquela percepção na criança não é uma simples reflexão nem o resultado de um processo de dados distribuídos. Ainda, é uma operação mais profunda na qual a criança organiza sua experiência de eventos externos - uma operação que não é propriamente nem lógica nem predicativa (MerleauPonty, 2003, p. 98).

Existem algumas menções adicionais de Michotte em $O$ Visível e o Invisível a respeito do movimento animado, e Merleau-Ponty realmente declara "que a teoria moderna da percepção é uma fenomenologia (Michotte) e descobre o ser bruto, o mundo vertical” (Merleau-Ponty, 1968, p. 200).

É curioso que, dado seu papel em ciência e tecnologia também na vida cotidiana, a causalidade recebe muita pouca atenção na fenomenologia. Talvez, a maioria dos fenomenólogos atira o bebê da causalidade como percebida na passividade primária fora do banho da explicação causal naturalista cientificamente construída e também o naturalismo. Mas claramente ela pode ser encontrada em uma abordagem descritivo-reflexiva, especialmente aquela amparada por uma apreciação pelas investigações psicológico-experimentais de Albert Michotte.

\section{Referências Bibliográficas}

Boring, E.G. (1952) (Ed.). Albert Michotte van den Berck, $A$ History of Psychology in Autobiography, v. IV, Worcester: Clark University Press.

Embree, L. (1980). Merleau-Ponty's Examination of Gestalt Psychology. Research in Phenomenology, n. 10, p. 89-121.

Merleau-Ponty, M. (1964). Maurice Merleau-Ponty à la Sorbonne, Resumée des ses cours établi par des étudients et apprové par lui-même, Bulletin de Psychologie, v. XVIII.

Merleau-Ponty, M. (1968). The Visible and the Invisible. Evanston, III: Northwestern University Press.

Merleau-Ponty, M. (2003). Nature : Course Notes from the College de France. Evanston, III: Northwestern University Press.

Michotte, A. (1963). The Perception of Causality, New York: Basic Books. 
Spiegelberg, H. (1972). Phenomenology in Psychology and Psychiatry, Evanston, Illinois: Northwestern University Press.

Thinès, G., Costall, A. \& Butterworth, G. (1991) (Ed.). Michotte’s Experimental Phenomenology of Perception, Hillsdale, New Jersey: Laurence Erlbaum Associates.

Lester Embree - professor do Departamento de Filosofia do Florida Atlantic University, em Boca Ratón, Florida (Estados Unidos). PhD em Filosofia pelo New School for Social Research, sob orientação de Aron Gurwitsch, é um dos fundadores e atualmente um dos diretores do Center of Advanced Research in Phenomenology (http://www.phenomenologycenter.org). Autor de diversos textos em Fenomenologia. Email: embree@fau.edu.

Recebido em 11.06.07

Aceito em 15.10.07 